\title{
Structural Properties of the Zno Nanorods on PES Substrate by Hydrothermal Method According to Growth Temperature
}

\author{
JaeHyeon $\mathrm{Oh}^{1}$, JaeHeon Ock ${ }^{1}$, SangHyun Kim ${ }^{1}$, Nakwon Jang ${ }^{1}$ and SeongHwan Lee ${ }^{2}$ \\ ${ }^{1}$ Division of Electrical and Electronics Engineering, \\ Korea Maritime and Ocean University, Busan, 606-791, Korea \\ ${ }^{2}$ Division of Energy and Electrical Engineering, Uiduk University, Kyungju, 780-713, Korea
}

\begin{abstract}
We study the characterization of $\mathrm{ZnO}$ nanorods according to temperature. However, the the amorphous crystal structure as well as the surface morphology of polyestersulfone (PES) substrate is not good. Therefore, we introduced a $\mathrm{ZnO}$ buffer layer to facilitate $\mathrm{ZnO}$ nanorods growth. Furthermore, in order to control characteristic on the growth of $\mathrm{ZnO}$ nanorods, we grew $\mathrm{ZnO}$ nanorods on PES in various growth temperature. Additionally, we analyzed the structural characteristics with temperature using XRD, FE-SEM for the fabrication of flexible devices.
\end{abstract}

Keywords: flexible, ZnO, nanorod, hydrothermal method

\section{Introduction}

Flexible electronic devices have not only the advantage over existing ones because of flexibility and economic efficiency by ultra-lighten but also applied possibility of many ways. Therefore, Flexible electronic devices will large influence coming electronic industry. Flexible electronic devices should be made under comparatively low temperature condition because of plastic's low melting point. So it is difficult to obtain good properties.

Recently $\mathrm{ZnO}$, possible to process in low temperature condition and have fast electron mobility, is received attention for material used in the flexible electronic devices. $\mathrm{ZnO}$, representative II-VI oxide semiconductor, is chemically stable material having high exciton energy and comparatively wide band gap energy. Also, $\mathrm{ZnO}$ is taking center stage under the field of TCO, TTFT, solar cell because it has high light transmittance and electric conductivity. And it is being done a study about band gap engineering for increasing bandgap energy to apply photoelectric element in UV field.

Nano technology has received attention with rapidly changing technologies since 1990. Since Nano technology has good availability and wide variety, it is expected to be a foundation of new technology. Especially Nano technology in semiconductor field will be a innovated technology, for example, when we make high density integrated chips by making electronic elements made by nanostructures. But Nano technology has many technical problems to be solved such as precise synthetic technique, construction technique, etc.

Nanostructure is classed as nano thinfilm, one-dimensional nanostructure such as nanowire, nanorod, nanoribbon and etc and zero-dimensional nanostructure such as macromolecule, quantum dot. One-dimensional nanostructure of these is possible to apply directly to electronic-photonic element such as transistors, diodes, sensor, solar cell and etc. Therefore, such studies are proceeding for putting practical use.

Growing method of one-dimensional $\mathrm{ZnO}$ nanostructure is possible to approach a way of bottom-up. Methods are proposed variously because nanostructure grows differently depending on shape or size of that. Preexisting methods such as MBE(molecular beam epitaxy), PECVD(Plasma-enhanced chemical vapor deposition), PLD(pulsed laser deposition) are expensive and complex operation by using very high temperature and pressure system. In contrast, hydrothermal method is one of methods to obtain a solid solution compound having uniform crystalline. That method can be used under low temperature and pressure condition by using comparatively cheap and straightforward equipment. 


\section{Experimental Details}

\subsection{The deposition of $\mathrm{ZnO}$ buffer layer}

In this experiment, we used an RF magnetron sputter system for the deposition of the $\mathrm{ZnO}$ buffer layer. Before deposition, the substrate, which was PES, was $1 \mathrm{~cm} \times 1 \mathrm{~cm}$. In addition, the PES substrate was cleaned with an ultra-sonic cleaner using methanol and DI water. The base pressure of the chamber was maintained at 6.0X10-6 Torr. We also supplied the Ar gas at $20 \mathrm{sccm}$ to create plasma. After that, the deposition pressure of the chamber was maintained at 5 mTorr. However, the crystal structure as well as the surface morphology is not good in PES substrate. Fig. 1 is Schematic diagram of RF magnetron sputter system and TABLE 1 is Deposition conditions of $\mathrm{ZnO}$ buffer layer.

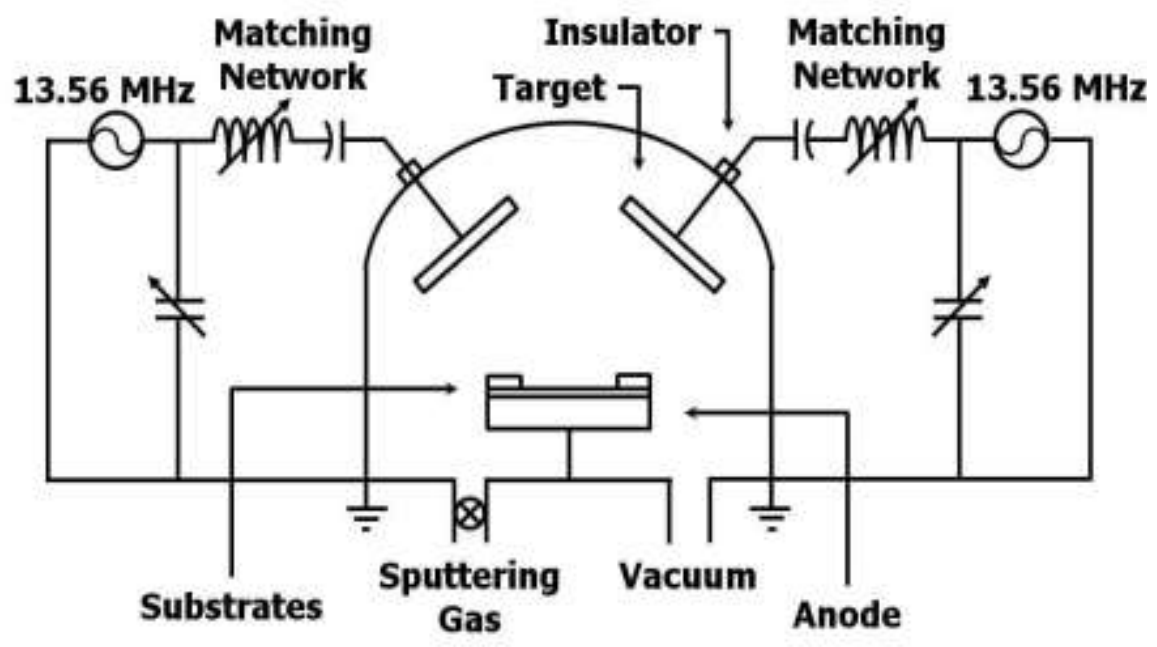

Fig. 1: Schematic diagram of RF magnetron Sputter sytem

TABLE I: Deposition conditions of $\mathrm{ZnO}$ buffer layer on PES substrate

\begin{tabular}{ll}
\hline \hline Property & Settings \\
\hline Target & ZnO \\
Substrate & PES \\
Power & $100 \mathrm{~W}$ \\
Deposition time & 20 minute \\
Thickness & $100 \mathrm{~nm}$ \\
Deposition temperature & Room temperature \\
\hline \hline
\end{tabular}

\subsection{Growth of $\mathrm{ZnO}$ nanorods}

For growth of $\mathrm{ZnO}$ nanorods, the solution of $\mathrm{ZnO}$ was produced using zinc nitrate hexahydrate, hexamethylenediamine (HMT), and deionized (DI) water. The amount of zinc nitrate hexahydrate and HMT is fixed at $0.3 \mathrm{M} \%$. And we stirred two solutions at each beaker during 15 minutes. After that, we put the flat bottom flask in large beaker, and warm up in a double boiler system using Si oil on the hot plate. And the PES substrate substrate was placed upside down in the flask, because we choose the growth methods of bottom to up. The growth conditions of $\mathrm{ZnO}$ are shown Table 2 and Fig. 2 is Schematic diagram of hydrothermal method.

TABLE II: Growth conditions of $\mathrm{ZnO}$ nanorods

\begin{tabular}{ll}
\hline \hline Property & Settings \\
\hline Target & ZnO \\
Substrate & PES \\
Power & $100 \mathrm{~W}$ \\
Deposition time & 20 minute \\
Thickness & $100 \mathrm{~nm}$ \\
Deposition temperature & Room temperature \\
\hline \hline
\end{tabular}




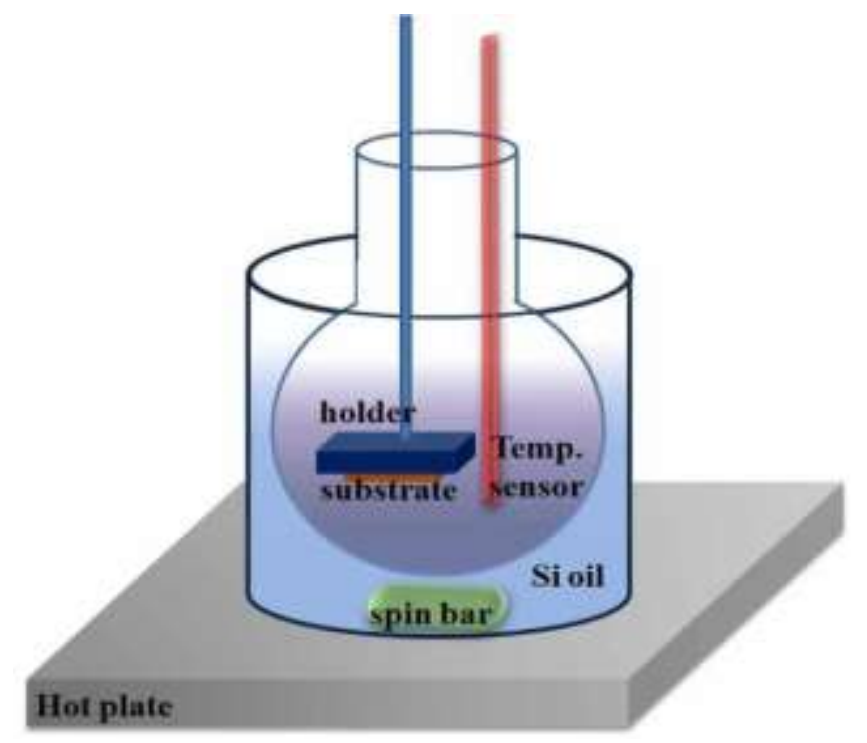

Fig. 2: Schematic diagram of hydrothermal method.

\section{Results And Discussion}

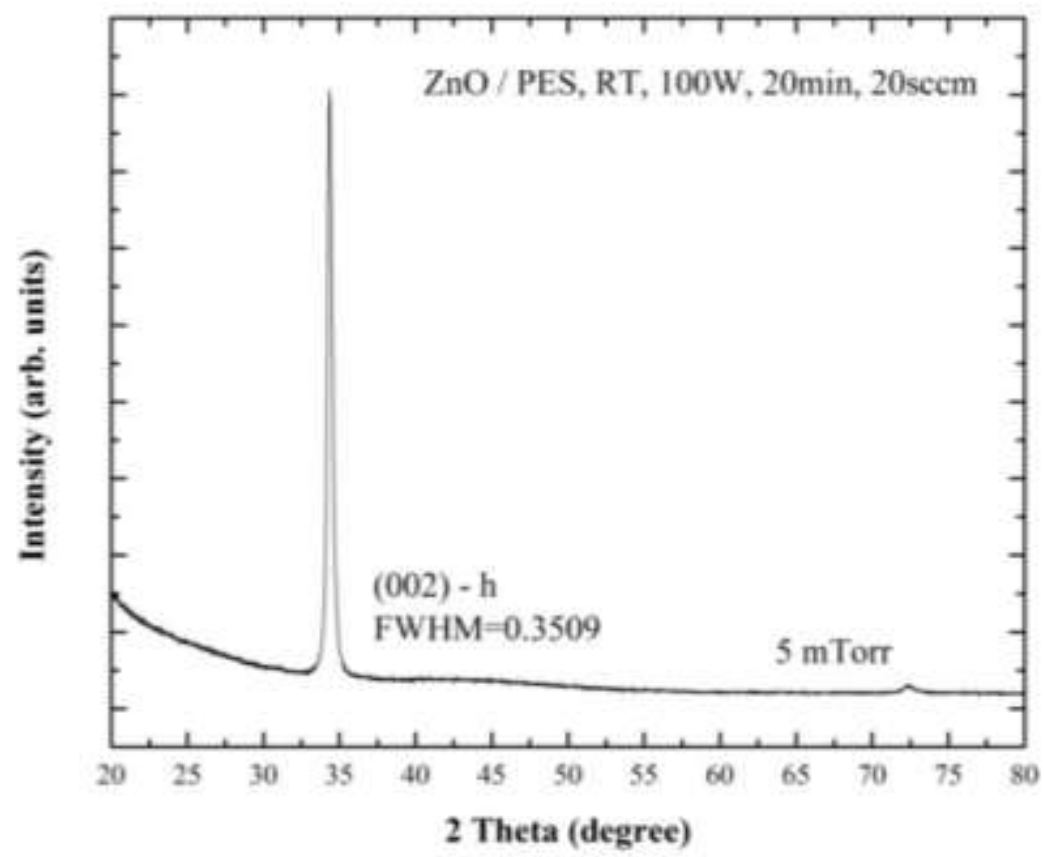

Fig. 3: The result of XRD about $\mathrm{ZnO}$ buffer layer.

The PES substrate has amorphous structure. So for getting the uniformly $\mathrm{ZnO}$ nanorods, it needs to buffer layer. We grow the $\mathrm{ZnO}$ buffer layer on the PES substrate by the RF magnetron sputter system. First, we analyzed the $\mathrm{ZnO}$ buffer layer. The structural properties of $\mathrm{ZnO}$ buffer layer are analyzed by XRD. The result of $\mathrm{XRD}$ is shown in Fig 3. The peak of $\mathrm{ZnO}$ buffer layer is located nearby $34.5^{\circ}$, the intensity of $\mathrm{ZnO}$ buffer layer is so high value, and the FWHM(Full Width at Half Maximum) is 0.3509. So, the structural properties of ZnO buffer layer had great structural properties at this deposition condition. So, ZnO nanorods was grown using this $\mathrm{ZnO}$ buffer layer on PES substrate. 


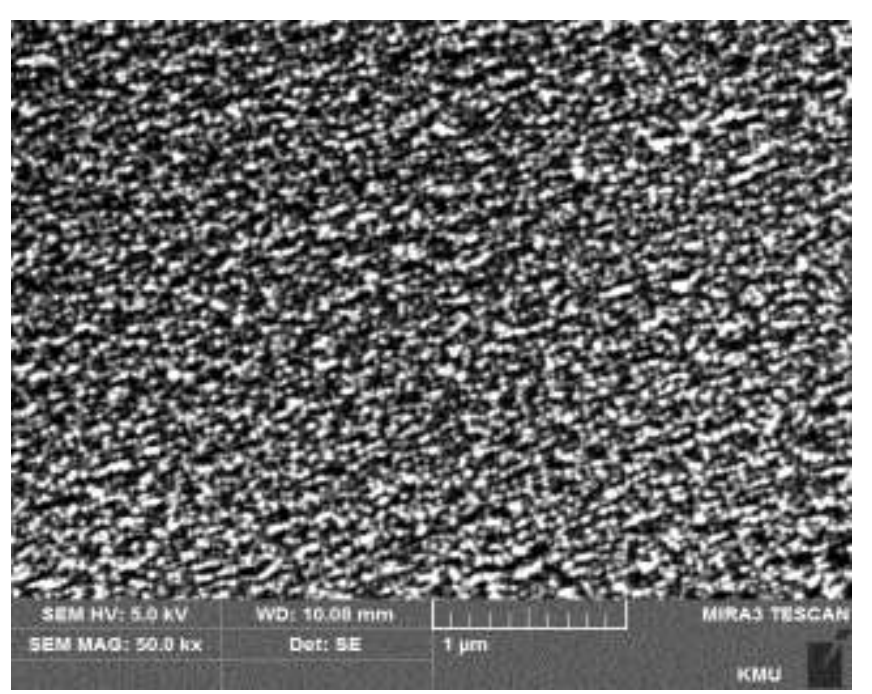

(a)

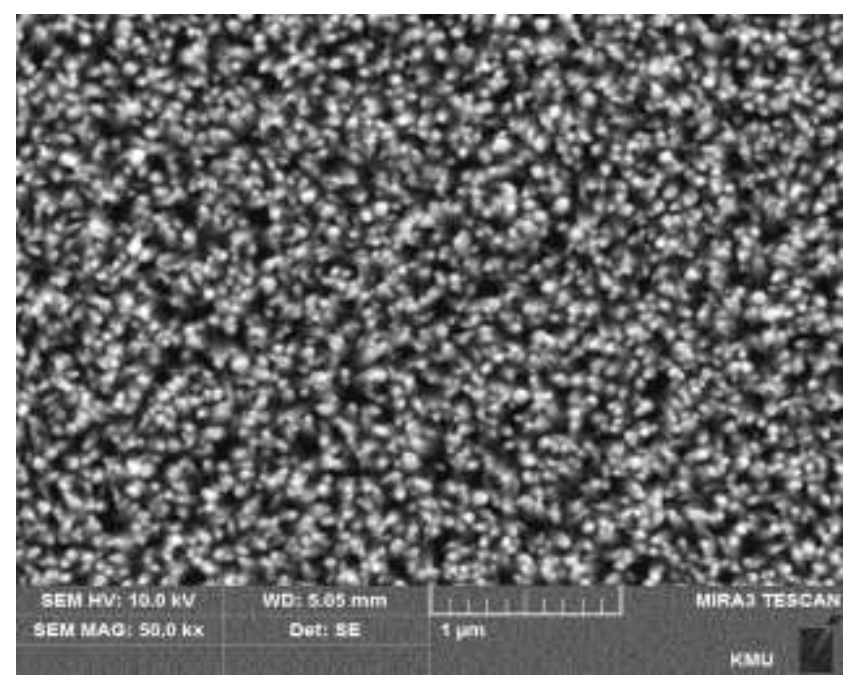

(c)

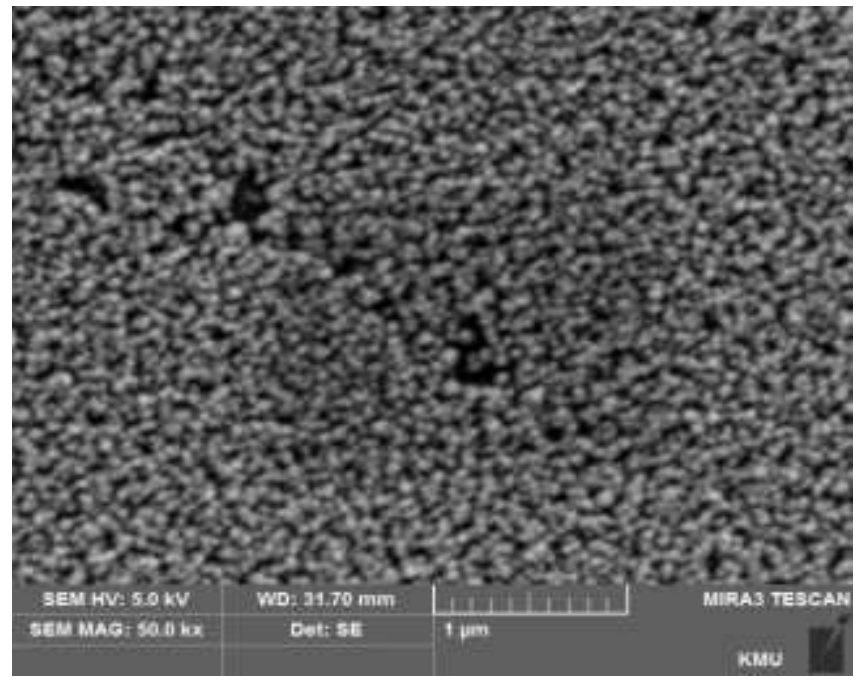

(b)

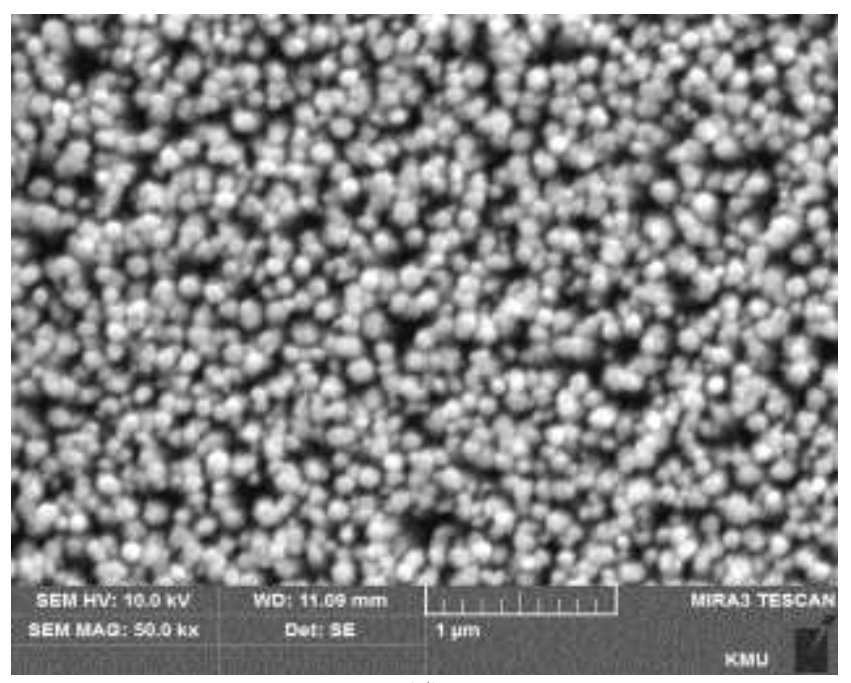

(d)

Fig. 4: The result of FE-SEM about $\mathrm{ZnO}$ nanorods according to temperature (a) $90^{\circ} \mathrm{C}$, (b) $110^{\circ} \mathrm{C}$, (c) $130^{\circ} \mathrm{C}$, and (d) $150^{\circ} \mathrm{C}$ The result of XRD about $\mathrm{ZnO}$ buffer layer.

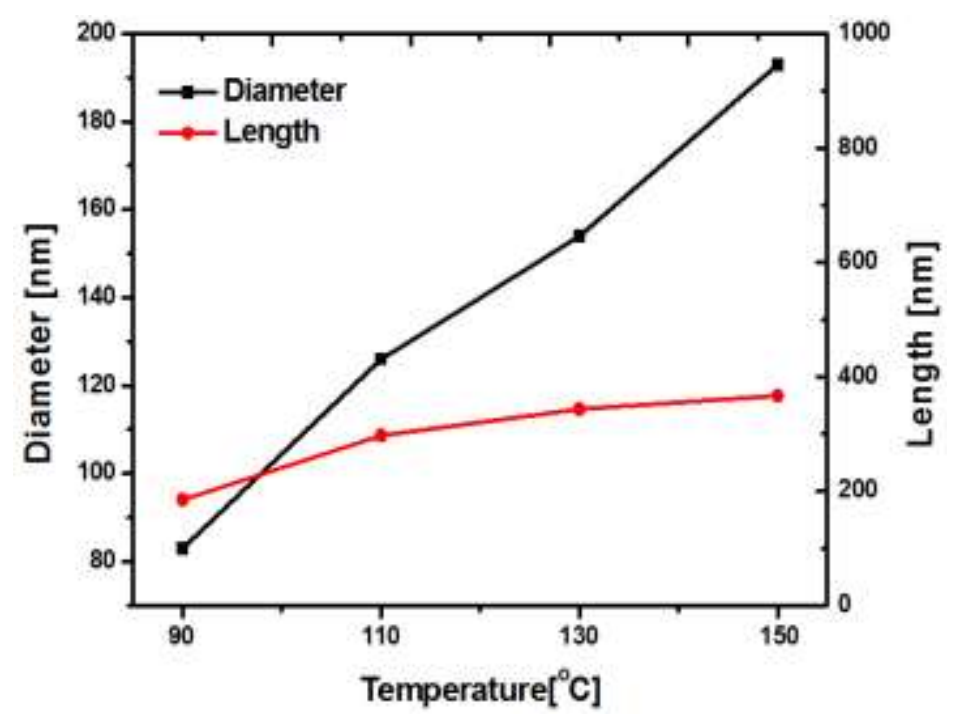

Fig. 5: The length and diameter of $\mathrm{ZnO}$ nanorods according to temperature 
Fig. 4 is a SEM image for observing the image of the fine $\mathrm{ZnO}$ nanorods according to the temperature of growth, the size of each nanorods are shown at graph in Fig. 5. And the density of $\mathrm{ZnO}$ nanorods is higher at temperature of $90^{\circ} \mathrm{C}$ than temperature of $150^{\circ} \mathrm{C}$. The diameter of the $\mathrm{ZnO}$ nanorods grown with increasing the density increases linearly until $150^{\circ} \mathrm{C}$ of the maximum temperature and, the change of length had a relatively uniform size, regardless of the temperature of about $180 \mathrm{~nm}$. Thus, $\mathrm{ZnO}$ nanorods are grown First of the vertical direction, after those particles of $\mathrm{ZnO}$ was supplied to the growth in the radial direction. So Growth in the supersaturated solution shows the active shape in the radial direction. And the structural properties of $\mathrm{ZnO}$ nanorods can be seen that substantially vertically grown.

\section{References}

[1] R. L. Hoffman, B. J. Norris, and J. F. Wager, "ZnO-Based Transparent Thin-Film Transistors," Appl. Phys. Lett., 82, 733-735 (2003) http://dx.doi.org/10.1063/1.1542677

[2] D. C. Reynolds, D. C. Look and B. Jogai, Solid State Commun. 99, 1996, pp.873 http://dx.doi.org/10.1016/0038-1098(96)00340-7

[3] D. C. Look, Mater. Sci. Eng. B. 80, 2001, pp.383 http://dx.doi.org/10.1016/S0921-5107(00)00604-8

[4] H. S. Kang, J. W. Kim and S. Y. Lee, J. Appl. Phys. 95, 2004, pp.1246 http://dx.doi.org/10.1063/1.1669213

[5] T. Takagi, H. Tanaka, S. Fujita, and S. Fujita, Jpn. J. Appl. Phys. 42, L401, 2003 http://dx.doi.org/10.1143/JJAP.42.L401

[6] Y. Chen, D. Bangnall and T. Yao, Master. Sci. Eng. B75, 2000, pp.190 http://dx.doi.org/10.1016/S0921-5107(00)00372-X

[7] M. joseph, H. Tabata and T. Kawai, Japanese Journal of Applied Physics Part 2 Letters 38, L1205 ,1999

[8] M. H. Francombe and S. V. krishnaswamy, J. Vac. Sci. Technol. A8, 1990, pp.1382 http://dx.doi.org/10.1116/1.576886

[9] S. Limpijumnong and S. Jungthawan, Phys. Rev. B 70, 054104,2004 http://dx.doi.org/10.1103/PhysRevB.70.054104 